\title{
An Empirical Analysis of Provincial Productivity in China (1979-2001) ${ }^{1}$
}

\author{
JiNGHAI ZHENG \\ Department of Economics \\ Göteborg University, Box 640, S-405 30 Göteborg, Sweden \\ (mailing address as above) \\ E-mail: Jinghai.Zheng@economics.gu.se \\ Angang Hu \\ Center for China Studies \\ School of Public Policy and Management \\ Tsinghua University, Beijing, China \\ E-mail: anganghu@mail.Tsinghua.edu.cn \\ Working Paper in Economics (SwoPEc) no.127, ISSN 1403-2465 \\ Revised version March 2004
}

\begin{abstract}
This study analyzes provincial productivity growth in China for the period of 1979-2001. The Malmquist Index approach allows us to decompose productivity growth into two components, technical progress and efficiency change. Considerable productivity growth was found for most of the data period, but it was accomplished mainly through technical progress rather than efficiency improvement. Although China's capital stock has been accumulated at the speed of a historical record in recent years, our findings show that TFP growth slowed significantly during 1995-2001. The study thus raises serious questions on whether China's recent growth pattern is consistent with its comparative advantages, and whether its reliance on capital accumulation can be sustained in the long run.
\end{abstract}

Journal of Economic Literature Classification Numbers: O47, O53, D24

Key words: Productivity, capital deepening, China

\footnotetext{
${ }^{1}$ The authors would like to thank Xiaoxuan Liu and Arne Bigsten for their support to and help with this research project. Assistance provided by Ms Xin Sheng and Mr Chunbo Li are appreciated.
} 


\section{Introduction}

Over the past two decades, China has been one of the fastest growing economies in the world. Studies suggest that total factor productivity (TFP) growth has been a very import factor behind the increase in output growth during the reform period and improvements in TFP account for 30 to 58 percent of the recent growth (e.g., World Bank, 1997; Madisson, 1998). It means that productivity improvements account for a significant proportion of the dramatic increase over the past 20 years in the standard of living in China. Both the annual increase in productivity and its contribution to growth over a sustained period are among the highest in the world, including the developed countries (Bhattasali, 2001).

However, some economists have considerable doubts on the nature of China's past growth experience that has been regarded so far in the majority of the literature as productivity driven. Sachs and Woo (1997) pointed out that China's broad growth performance is in line with the performance of other East Asian Economies, which is attributable mainly to factor accumulations. Young (2000) questioned the performance of China's growth by linking his findings on the convergence of the provincial industrial structure to the fragmentation of the domestic market and the distortion of regional production away from patterns of comparative advantage. Young (2003) also shows that one can reduce the growth rate during the reform period to levels previously experienced by other rapidly growing economies, so that total factor productivity growth in the nonagricultural economy are found to be 1.4 percent per year; a respectable performance, but by no means extraordinary. Liu (2000) believes that much of the productivity gains in the past two decades stemmed from the rectification of resource misallocations that were the legacy of the central planning era and from narrowing technology gaps between China and developed economies. Over time, as China moves closer to a market economy, such gains will inevitably diminish.

In fact if one pays attention to the aggregate statistics of recent years, there are a few worrisome signs. Official statistics shows that between 1995 and 2001 the 8.2\% GDP growth rate was slower than the $9.8 \%$ for $1978-95$; the growth rate of GDP per capita, $7.3 \%$ was also slower than the previous $8.4 \%$. Although capital stock had been accumulated at a speed of historical record, increasing by $11.8 \%$ annually, labor productivity growth unexpectedly decreased to $7.0 \%$ from $7.2 \%$ for $1978-95$ and employment growth reduced to $1.2 \%$ from 
$2.4 \%$ in the previous period - an indication of accelerating "capital deepening" (Hu, 2003). If we perform a simple growth accounting exercise based on the official data, using the weight for capital of 0.6 and labor of 0.4 , a surprising result is that there has been a dramatic decrease in the growth rate of TFP, from $3.16 \%$ for $1978-1995$ to only $0.6 \%$ for $1995-2001$. This observation seems to confirm the view held by some Chinese economists that China's economic growth during the 1990s has followed a different pattern in comparison with the 1980s.

Moreover, our calculation also demonstrates that the methodologies used in the literature to estimate TFP growth should be treated with caution. For example, if we had used different weights in the above calculation, the dramatic decrease in TFP growth in recent years could have gone unnoticed. This reminds us that the two methods employed in most of the studies in the ongoing debate about China's productivity performance, growth accounting and aggregate time series production function estimation, suffer from some major drawbacks. In this study we intend to add to the international literature on the Asian productivity debate in general and on the Chinese productivity debate in particular by employing Malmquist indexes to a sample of Chinese provinces. The Malmquist index approach suggested in Färe et al. (1994) belongs to the category of frontier production function estimations, it is free of the strong assumptions involved in the Divisia index approach of growth accounting. It also allows decomposing the change in TFP into technical progress and efficiency improvement. This distinction is fundamental for policy actions, especially in developing countries such as China.

Our major findings are as follows, considerable productivity growth was found for most of the data period (1979-2001), but it was accomplished mainly through technical progress rather than through efficiency improvement. In comparison with the period of 1979-1995, although China's capital stock has been accumulated at the speed of a historical record in recent years, our findings show that TFP growth has slowed significantly during 1995-2001. The study thus raises a number of serious questions on whether China's recent growth pattern is consistent with its comparative advantages, and whether its reliance on capital accumulation can be sustained in the long run. The plan of the paper is as follows. In section 2, we conduct a brief survey of the relevant literature on the Chinese productivity debate. In 
section 3, we borrow from the literature a detailed account of the factors that might affect the overall economic performance during the recent years, focusing on efficiency problems that have been widespread in the incompletely reformed system. Methodologies and data are discussed and introduced in section 4. Section 5 reports and analyzes the empirical results. Section 6 concludes.

\section{The Chinese Productivity Debate}

The revival of the interest in growth theory during the 1980s with the development of the new neo-classical endogenous growth models has opened new avenues of research and initiated several debates. The attempt to explain how some countries in East and Southeast Asia grew so formidably for 30 years, giving rise to the so-called 'East Asian Miracle', has produced one of the most interesting discussions in the field of growth in this decade (Felipe, 1999). Equally interesting is the debate on China, as Krugman (1994) points out in his well-known article on the myth of Asia's miracle that although China is still a very poor country, its population is so huge that it will become a major economic power if it achieves even a fraction of Western productivity levels.

Several studies including the ones by World Bank (1997) and Maddison (1998) suggest that improvements in total factor productivity account for 30 to 58 percent of the recent growth. However, other researchers have provided less favorable statistical and analytical explanations. Krugman (1994) pointed out that accounting for China's boom is difficult because the quality of the numbers is extremely poor. In addition, if one measures growth from before the Cultural Revolution from 1964, the picture looks more like the East Asian "tigers": only modest growth in efficiency, with most of the growth driven by inputs. Sachs and Woo (1997) made a similar point on the basis of institutional analysis and their empirical estimates that China's broad growth performance is in line with the performance of other East Asian economies, which are characterized by, for example, low initial capital endowment, favorable physical access to international sea lanes, export orientation strategy, and a high proportion of the labor force in agriculture.

Recently Young (2003) has questioned the Chinese growth performance during the economic reform by focusing on the productivity performance of the nonagricultural sector. 
After making adjustments of Chinese official data, he shows that one can reduce the growth rate during the reform period to levels previously experienced by other rapidly growing economies, so that once one takes into account rising labor force participation, the transfer of labor out of agriculture, and improvements in educational attainment, labor and total factor productivity growth in the nonagricultural economy are found to be 2.6 and 1.4 percent per year, respectively; a respectable performance, but by no means extraordinary.

A more recent study by Wang and Yao (2003) constructed a measure of China's human capital stock over 1952-1999 and performed a growth accounting exercise. They found that the accumulation of human capital was quite rapid and contributed significantly to growth and welfare; after incorporating human capital, the growth of total factor productivity (TFP) still played a positive role in GDP growth in the reform period, while it was negative in the pre-reform period. The debate is still going on.

\section{Efficiency Problems of the Halfway Reform}

In addiction to the debate on the nature of China's growth performance of the past two decades, the growth patterns of recent years are also somewhat puzzling. On one hand, the economy has been able to continue to grow at about $8 \%$ per year. On the other hand, slower labor productivity growth accompanied with a historical record in the speed of capital accumulation seem to signal a decrease in TFP growth with accelerating "capital deepening". If we use the weight for capital of 0.6 and labor of 0.4 for growth accounting, a surprising result is that there has been a dramatic decrease in the growth rate of TFP, from $3.16 \%$ for 1978-1995 to only $0.6 \%$ for $1995-2001$. What could be the causes of this considerable TFP growth slow down?

A recent study by OECD (2002) indicates that the important engines that have driven China's growth in the past are losing their dynamism. The main reason is that China's economy has become badly fragmented and segmented, and this has led to increasing-under and inefficient utilization of resources. As Young pointed out that these are typical problems with a halfway reformed economic system: In a partially reformed economy, distortions beget distortions. Segments of the economy that are freed from centralized control respond to the rent-seeking opportunities implicit in the remaining distortions of the economy. The battle 
to capture, and then protect, these rents leads to the creation of new distortions, even as the reform process tries to move forward. In the case for China, under the plan, prices were skewed so as to concentrate profits, and hence revenue, in industry. As control over factor allocations was loosened, local governments throughout the economy sought to capture these rents by developing high margin industries. Continued reform, and growing interregional competition between duplicative industries, threatened the profitability of these industrial structures, leading local governments to impose a variety of interregional barriers to trade. Thus, the reform process led to the fragmentation of the domestic market and the distortion of the regional production away from patterns of comparative advantage (Young, 2000). Therefore, a substantial reallocation of resources among economic sectors and a major restructuring of the business sector will be needed to correct widespread inefficiencies. In general, the inefficient sectors that have caught much public attention are the industrial and the financial sectors. Here we present a shortened account of the problems in the two sectors documented in OECD (2002). Interested readers may as well refer to the more original Chinese literature on these issues, examples are Li (2003) for state enterprise (SOE) reforms, CCER (2000) for the issue of financial sector reform, and $\mathrm{Hu}$ (2002) for the relationship between the performance of the government and TFP growth.

\subsection{Problems with industries (OECD, 2002, pages 13-19)}

Industry financial performance has deteriorated sharply since the early 1990s. Profits fell to nearly zero in 1998, with more than one-third of enterprises making losses, and financial performance remains weak in many sectors. The deterioration has been pervasive and not simply confined to SOEs. The performance of collective enterprises has worsened nearly as much as that of SOEs; and the small and medium-size enterprises (SME) sector generally is in particularly dire straits.

The poor industry performance can be traced in part to the accumulation of policy burdens arising from the long-standing use of enterprises to accomplish social policy goals. These burdens, which amount to government resource extraction through regulation, include excess labor, high debt loads, and responsibilities for public pensions, housing, education, and other social benefits that in other countries are the responsibility of government or 
individuals. Policy burdens are heaviest on SOEs but they are also borne by rural enterprises (REs), i.e., SMEs in rural areas. Authorities have made significant progress in recent years in reducing excess labor and excess capacity and in reducing debt burdens of larger SOEs. However less progress has been made in reducing other policy burdens, and there has been much less improvement for other SOEs or non-state enterprises.

The biggest problem impairing industry performance is widespread inefficiency in enterprise operations. Presently, much of industry operates with inadequate resources that are poorly managed by the firms that control them and which are misallocated across firms. In contrast to formerly centrally planned economies in Eastern Europe, China's industry is characterized by widespread sub-optimal scale in production facilities, fragmentation and duplication. There are 200 separate producers of automobiles, most of which complete only a few thousand units per year. Much of the plant and equipment is outmoded. Economies of scope are also poorly exploited, as illustrated by the nearly 8000 independent cement firms in China compared to 110 in the United States, 51 in Russia, 58 in Brazil, and 106 in India.

Inadequate technology and limited capacity to innovate are particular weaknesses of much of Chinese industry. Technology standards for a large portion of domestic firms are below international standards. China devotes proportionately fewer resources, and produces less scientific outputs such as patents, than OECD countries, as well as other large developing countries such as India. Industry also plays a relatively smaller role in technology development and innovation. Moreover, the technology transferred by foreign enterprises to Chinese firms seems to have been limited in both amount and scope.

These inefficiencies are attributable to a range of factors at the firm level, in the external environment, and in the relation between government and business. The poorly skilled and insufficiently profit-motivated management that characterizes much of domestic business has neglected technology. Weak financial discipline, which has effectively presented firms and their government backers with a zero cost of capital, has been a major impetus to the development of unproductive and redundant capacity. The pre-reform policy of encouraging regional self-sufficiency together with low capital mobility has left a legacy of limited regional specialization in production. The resulting inefficiencies have persisted and accumulated because key corrective market mechanisms have been severely impaired. Exit 
via bankruptcy and liquidation has been relatively rare, although it is becoming more common; and regional protectionism and other administrative barriers have severely restricted the scope for value enhancing mergers and acquisitions (M\&A). These factors have become a mutually reinforcing vicious circle. Government interference leads to poor SOE management and inefficient operations, which foster low profits and high debt; this in turn makes it more difficult to restructure to improve efficiency and prompts government interventions that spread the problem by extracting resources from stronger enterprises to prop up those that are failing.

The contrast in performance among industry segments has likewise become starker. Large SOEs remaining under government control receive preferential treatment from the government and are often sheltered from competition, but their performance is often lackluster and their flexibility is constrained by government intervention in their management and by various policy burdens. A contrasting segment includes less favored SOEs and collectives that have become highly competitive in national, and in some cases international, markets, in large part because they have been freer of government interference, more exposed to market discipline, and better managed as a result. Between these groups lie a large portion of (mainly) SMEs in poor financial condition and in dire need of restructuring, but whose ability to restructure is circumscribed by limited access to financing and other impediments.

\subsection{Problems with the financial sector (OECD, 2002, pages 18-23)}

Although China's financial system has made important progress in recent years, it still performs inadequately in carrying out several of its basic functions in the economy. Savings appear to be mobilized reasonably effectively, but credit is inefficiently allocated. SOEs receive the bulk of funds allocated by the formal financial system, while non-state enterprises receive a much lower share than warranted by their importance in the overall economy. Non-commercial considerations, such as the need to sustain loss-making SOEs, continue to influence bank lending. There is limited diversity in financial outlets and capabilities. The inter-bank market and other available facilities provide only limited scope for transferring funds among financial institutions or regions. Insurance companies and other institutional investors are underdeveloped even compared with other emerging market economies such as 
India and Brazil. The government and other bond markets are small, fragmented, and illiquid, and the stock market, despite its rapid growth, is subject to limitations on access and trading that impair its effectiveness. Financial instruments to deal with liquidity fluctuations, manage risk, and provide for other specialized needs are limited.

The external discipline provided by the financial system has also been a major weakness. Years of government-mandated lending together with weak contract enforcement and bankruptcy regimes created a distorted credit culture. Government mandates and weak lending standards created "soft budget constraints" for many enterprises that were a major factor in the over-investment that occurred during 1992-94, and whose legacy of excess and inefficient capacity now afflicts the Chinese economy. Due in part to the limited development of capital markets, but also to government intervention in enterprise operations, the financial system lacks means to support enterprise restructuring, re-deploy resources, and provide a market for corporate control.

These weaknesses in the financial system are partly a reflection of the fact that China is still a developing country. However they also reflect the fact that evolution of the financial system has lagged that of the real economy. Despite the substantial growth of the non-state sector in the real economy, the financial system remains virtually entirely state-owned, with only a single privately owned domestic bank. The four major state-owned commercial banks (SOCBs) established in the early reform period to finance SOEs, and which are still heavily oriented toward this enterprise segment, dominate the financial system, accounting for nearly three-quarters of domestic lending.

Despite the carve out of non-performing loans in 2000, the SOCBs along with many other financial institutions almost certainly would have negative capital if their loan portfolios were valued realistically. Non-performing loans remaining with the SOCBs after the transfer of loans to bank asset management companies (BAMC) were nearly 27 per cent of total loans in mid 2001, and would probably be higher if the international accounting standards China is gradually introducing were fully applied. Joint stock banks also have high non-performing loans and rural credit co-operatives are widely acknowledged to be in especially bad shape. Bank profits have fallen steadily through the 1990 s to very low levels that would probably be close to zero, or even negative, for SOCBs if international accounting 
standards were applied.

In a proximate sense, the ongoing problems of financial institutions reflect the poor condition of their enterprise customers. A severe vicious circle has developed. Poor enterprise performance contributes to bank non-performing loans and lowers bank profits by eliminating much of their core market. Financial institutions themselves cannot hope to restore their financial solvency unless and until enterprise performance improves substantially. But high non-performing loans make it difficult for banks to provide the funds for the enterprise restructuring needed to improve their performance. Limited government revenues to facilitate SOE restructuring and its consequences continue to require bank lending to sustain loss-making SOEs. This in turn weakens efforts to improve the internal credit culture and commercial orientation of the banks, while blunting incentives of SOEs to improve their own governance and management.

\section{Methodology and Data}

The theoretical framework concerning our study is the neo-classical growth theory. Growth in this framework stems from two sources: factor accumulation and productivity (TFP) growth. The theoretical foundation of this approach is the production theory according to which an economy can grow by (1) deploying more inputs, labor and capital, to production and/or by (2) becoming more efficient, i.e. producing more output per unit of input. Input-driven growth is not sustainable because of the law of diminishing returns to capital. This leaves productivity as the sole viable engine of long-term economic growth (Liu, 2000). Therefore, the key point of the productivity debate on Asia as well as on China is the relative importance of each of these two components. In comparison with factor accumulation, the problems inherent in the estimation of TFP are not a simple issue, and hence most of the debate has focused on TFP (Felipe, 1999).

Usually aggregate TFP growths on China are studied with two mythologies, growth accounting and the aggregate time series production function estimation. The former has been used by the World Bank (1997), Hu and Khan (1997), Maddison (1998), Liu (2000), Wang and Yao (2003), Young (2003), while the latter by Chow (1988, 1993, 2002a, 2002b), Heytens and Zebregs (2003), Wang and Meng (2001). However, the two methodologies 
suffer from three major drawbacks. First, in the case of growth accounting fairly strong behavioral and institutional assumptions have to be maintained in order to calculate the rate of TFP growth. Second, none of the two approaches distinguish between the part of productivity growth due to technical progress and the part due to an increase in technical efficiency. Third, aggregate time series were used in most of the studies. With just about two score of observations, it is very difficult to include more than a few explanatory variables in the analyses.

In this study we use the Malmquist Index approach (Färe et al. 1994), which belongs to the category of frontier production function estimations. It is free of the strong assumptions involved in the Divisia index approach of growth accounting. Another major advantage of this approach is that it allows decomposing the change in TFP into technical progress and technical efficiency change; the former is associated with changes in the best-practice production frontier, and the latter with other productivity changes, such as learning by doing, improved managerial practices, and change in the efficiency with which a known technology is applied. This distinction is fundamental for policy actions, especially in developing countries, where identifying TFP growth with technical progress can miss the fact that technical efficiency change seems to be the most relevant component of the total change in TFP, and therefore, the introduction of new technologies without having realized the full potential of the existing ones might not be meaningful (Felipe, 1999). A third advantage of our study involves the panel data nature of the provincial sample. It provides extra degrees of freedom (more than 600 observations for the reform period) in analyzing the determinants of productivity growth, of technical progress, and of efficiency improvement.

Following Färe et al. (1994) to define the output-based Malmquist index of productivity change, we assume that, for each time period $t=1, \ldots, T$, the production technology $\mathbf{S}^{t}$ models the transformation of inputs, $\mathbf{x}^{t} \in \mathbf{R}_{+}^{N}$, into outputs, $\mathbf{y}^{t} \in \mathbf{R}_{+}^{M}$, as follows:

$$
\mathbf{S}^{t}=\left\{\left(\mathbf{x}^{t}, \mathbf{y}^{t}\right): \mathbf{x}^{t} \text { can produce } \mathbf{y}^{t}\right\}
$$

The output distance function is defined at $t$ as:

$$
\begin{aligned}
D_{\mathrm{o}}{ }^{t}\left(\mathbf{x}^{t}, \mathbf{y}^{t}\right) & =\inf \left\{\theta:\left(\mathbf{x}^{t}, \mathbf{y}^{t} / \theta\right) \in \mathbf{S}^{t}\right\} . \\
= & \left(\sup \left\{\theta:\left(\mathbf{x}^{t}, \theta \mathbf{y}^{t}\right) \in \mathbf{S}^{t}\right\}\right)^{-1} .
\end{aligned}
$$


Note that $D_{\mathrm{o}}{ }^{t}\left(\mathbf{x}^{t}, \boldsymbol{y}^{t}\right) \leq 1$ if and only if $\left(\mathbf{x}^{t}, \mathbf{y}^{t}\right) \in \mathbf{S}^{t}$. In addition, $D_{\mathrm{o}}{ }^{t}\left(\mathbf{x}^{t}, \mathbf{y}^{t}\right)=1$ if and only if $\left(\mathbf{x}^{t}\right.$, $\mathbf{y}^{t}$ ) is on the boundary or frontier of the technology. According to Farrell (1957), this occurs when production is technically efficient. In the case of a single input and one output, under constant returns to scale, maximum feasible output is achieved when average productivity, $y / x$, is maximized. In our empirical work, that maximum is the best practice or highest productivity observed in our sample and is determined using DEA techniques.

To define the Malmquist index, we characterize a distance function with respect to two different time periods as follows:

$$
D_{\mathrm{o}}{ }^{t}\left(\mathbf{x}^{t+1}, \mathbf{y}^{t+1}\right)=\inf \left\{\theta:\left(\mathbf{x}^{t+1}, \boldsymbol{y}^{t+1} / \theta\right) \in \mathbf{S}^{t}\right\} .
$$

This function measures the maximal proportional change in outputs required to make $\left(\mathbf{x}^{t+1}, \mathbf{y}^{t+1}\right)$ feasible in relation to the reference or benchmark technology at $t$. Similarly, a distance function that measures the maximal proportional change in output required to make $\left(\mathbf{x}^{t}, \mathbf{y}^{t}\right)$ feasible in relation to the technology at $t+1$, denoted $D_{\mathrm{o}}{ }^{t+1}\left(\mathbf{x}^{t}, \mathbf{y}^{t}\right)$ may be defined. In order to avoid choosing an arbitrary benchmark between $t$ and $t+1$, we specify the output-based Malmquist productivity change index as the geometric mean of two Malmquist productivity indexes, one with technology at $t$ and the other at $t+1$ as benchmarks, as follows:

$$
M_{\mathrm{o}}\left(\mathbf{x}^{t+1}, \mathbf{y}^{t+1}, \mathbf{x}^{t}, \mathbf{y}^{t}\right)=\left[\left(\frac{D_{\mathrm{o}}^{t}\left(\mathbf{x}^{t+1}, \mathbf{y}^{t+1}\right)}{D_{\mathrm{o}}^{t}\left(\mathbf{x}^{t}, \mathbf{y}^{t}\right)}\right)\left(\frac{D_{\mathrm{o}}^{t+1}\left(\mathbf{x}^{t+1}, \mathbf{y}^{t+1}\right)}{D_{\mathrm{o}}^{t+1}\left(\mathbf{x}^{t}, \mathbf{y}^{t}\right)}\right)\right]^{1 / 2} .
$$

In all definitions concerning Malmquist indexes, we assume constant returns to scale for the technology as suggested in Färe and Grosskopf (1996). The Malmquist productivity index in (4) can be disaggregated multiplicatively into two component measures:

$$
\mathrm{EFFCH}=\frac{D_{\mathrm{o}}^{t+1}\left(\mathbf{x}^{t+1}, \mathbf{y}^{t+1}\right)}{D_{\mathrm{o}}^{t}\left(\mathbf{x}^{t}, \mathbf{y}^{t}\right)},
$$

and

$$
\mathrm{TECH}=\left(\frac{D_{\mathrm{o}}^{t}\left(\mathbf{x}^{t+1}, \mathbf{y}^{t+1}\right)}{D_{\mathrm{o}}^{t+1}\left(\mathbf{x}^{t+1}, \mathbf{y}^{t+1}\right)} \frac{D_{\mathrm{o}}^{t}\left(\mathbf{x}^{t}, \mathbf{y}^{t}\right)}{D_{\mathrm{o}}^{t+1}\left(\mathbf{x}^{t}, \mathbf{y}^{t}\right)}\right)^{1 / 2},
$$

where the expression in (5) measures the change in efficiency between periods $t$ and $t+1$, which we denote efficiency change. Expression (6) captures shifts in the frontier technology, which we denote to be the technical change component; values less than one in both cases 
signify deterioration in productivity. We calculate the Malmquist productivity index using non-parametric programming techniques. We assume that there are $k=1, \ldots, K$ enterprises using $n=1, \ldots, N$ inputs $x_{n}^{k, t}$ at each time period $t=1, \ldots, T$. These inputs are used to produce $m=1, \ldots, M$ outputs $y_{m}^{k, t}$. Each observation of inputs and outputs is strictly positive and we assume that the number of observations remains constant over all years, although this is usually not the case with our data. The reference, or frontier, technology in period $t$ is constructed from the data as:

$$
\begin{array}{cr}
\mathbf{S}^{t}=\left\{\left(\mathbf{x}^{t}, \mathbf{y}^{t}\right): y_{m}^{t} \leq \sum_{k=1}^{K} z^{k, t} y_{m}^{k, t}\right. & m=1, \ldots, M, \\
\sum_{k}^{K} z^{k, t} x_{n}^{k, t} \leq x_{n}^{t} & n=1, \ldots, N, \text { and } \\
z^{k, t} \geq 0 & k=1, \ldots, K\} .
\end{array}
$$

It exhibits constant returns to scale and strong disposability of inputs and outputs (Färe and Grosskopf, 1996).

To calculate the productivity of enterprise $k$ ' between $t$ and $t+1$, we solve four different linear-programming problems: $D_{\mathrm{o}}{ }^{t}\left(\mathbf{x}^{t}, \mathbf{y}^{t}\right), \quad D_{\mathrm{o}}{ }^{t+1}\left(\mathbf{x}^{t}, \mathbf{y}^{t}\right), \quad D_{\mathrm{o}}{ }^{t}\left(\mathbf{x}^{t+1}, \mathbf{y}^{t+1}\right), \quad$ and $D_{\mathrm{o}}{ }^{t+1}\left(\mathbf{x}^{t+1}, \mathbf{y}^{t+1}\right)$. For each $k^{\prime}=1, \ldots, K$,

$$
\left(D_{\mathrm{o}}^{t}\left(\mathbf{x}^{k^{\prime}, t}, \mathbf{y}^{k^{\prime}, t}\right)\right)^{-1}=\max \theta^{k^{\prime}}
$$

subject to :

$$
\begin{array}{lc}
\theta^{k^{\prime}} y_{m}^{k^{\prime}, t} \leq \sum_{k=1}^{K} z^{k, t} y_{m}^{k, t} & m=1, \ldots, M, \\
\sum_{k=1}^{K} z^{k, t} x_{n}^{k, t} \leq x_{n}^{k^{\prime}, t} & n=1, \ldots, N, \text { and } \\
z^{k, t} \geq 0 & k=1, \ldots, K .
\end{array}
$$

This linear programming problem is the basis for DEA and the distance function estimates are referred to as DEA efficiency estimates in the literature.

Two of the distance functions used to construct the Malmquist index require information from two periods. The first of these is computed for observation $k$ as: 


$$
\left(D_{\mathrm{o}}^{t}\left(\mathbf{x}^{k^{\prime}, t+1}, \mathbf{y}^{k^{\prime}, t+1}\right)\right)^{-1}=\max \theta^{k^{\prime}}
$$

subject to:

$$
\begin{array}{lc}
\theta^{k^{\prime}} y_{m}^{k^{\prime}, t+1} \leq \sum_{k=1}^{K} z^{k, t} y_{m}^{k, t} & m=1, \ldots, M, \\
\sum_{k=1}^{K} z^{k, t} x_{n}^{k, t} \leq x_{n}^{k^{\prime}, t+1} & n=1, \ldots, N, \text { and } \\
z^{k, t} \geq 0 & k=1, \ldots, K .
\end{array}
$$

In empirical applications, the above formulations may produce results of technical regress, which are usually difficult to interpret. In this study, when the frontier for year $t+1$ is generated, the best practice observations from the year $t$ will also be included to impose a restriction of no technological regress (Zheng, Liu, and Bigsten, 2003).

There have been quite a few studies on economic growth in China using provincial data and the models of Mandiw-Borro type growth empirics. However, studies on provincial productivity performance are not as many. For example, there are growth accounting studies by Wang and $\mathrm{Hu}$ (1999), part of the results presented in Ezaki and Sun(1999), Wu (2000 and 2003), and the most recently Lin and Liu (2003). Data used in these studies are from official statistical yearbooks and our case is no exception. Our data came mainly from two publications: data for 1979-1998 were chosen from the Collections of Statistics for New China of 50 Years, SSB (1991); data for 1999-2001 from the China Statistical Yearbook (SSB, 2000). Part of the data has been used for growth accounting in Wang and $\mathrm{Hu}$ (1999). Since the Malmquist Index model we use belongs to the categories of frontier production function estimations, it involves basic variables such as output (GDP), labor, and capital, which are also used in the growth accounting practice.

By following Wang and $\mathrm{Hu}$ (1999), we use provincial GDP in 1978-fixed price as the measure for output. Since we do not have working hour measure of the labor force, numbers of the employed in the labor force are used as the labor measure. We use fixed capital stock in 1978-fixed price as the measure for capital. Interested readers may refer to Wang and $\mathrm{Hu}$ (1999) for details of the data. 


\section{Analyses of Empirical Results}

The main empirical results are presented in Table 1 through Table 6. Table 1 contains the provincial average technical efficiency levels over time, and Table 2 the provincial average rate of productivity growth and its components over time. Tables 3 to 6 divide the estimates into two periods, the 1980s and the 1990s. Table 3 reports the average technical efficiency during the two periods for every province in the data set, while Tables 4 and 5 give provincial TFP growth rate and its components for the 1980s and the 1990s. Table 6 lists the accumulated TFP growth for the entire data period. The last rows in these four tables are provincial averages.

The purpose of the analysis here is to determine the trends and the nature of China's productivity growth during economic reform. We will see that a significant slow down in TFP growth observed in the aggregate time series is once again confirmed with the provincial data and the use of the Malmquist Index methodology. The nature of the productivity growth is discussed through examination of the components of the TFP growth, i.e., technical progress and efficiency change. To distinguish between the micro concept of technical progress and the movement of provincial production frontier in the aggregate, we will sometimes use quotation marks to refer to the technical progress measured from the provincial data.

\subsection{The Trend in TFP growth}

Table 1 shows that the provincial average technical efficiency did not increase during the 22 years between 1979 and $2001 .^{2}$ It was $83.62 \%$ in 1979 and $82.15 \%$ in 2001 . However, the standard deviation appears to have an obvious increasing trend, from 0.0683 in 1979 to 0.1545 in 2001. The minimum value of technical efficiency (CRS) decreased to 0.51 in 1991 from 0.75 in 1979 , and since 1992 the minimum values have all been less than 0.50 . Table 3 shows that on average, the technical efficiency level of 0.811 in the 1990 s is slightly higher than that of 0.795 during the 1980 s.

\footnotetext{
${ }^{2}$ Since the DEA efficiency estimate, $0<D_{0}{ }^{t}\left(\mathbf{x}^{t}, \mathbf{y}^{t}\right) \leq 1$, is the reciprocal of the Farrell technical efficiency measure, we use it directly as our technical efficiency measure following Førsund and Hjalmarsson (1979).
} 
The last row in Table 4 indicates that TFP grew at a rate of $4.94 \%$ per annual during the 1980s, while it was only $1.85 \%$ during the 1990s (see the last row in Table 5). From 1998, TFP growth rate appeared negative twice, 1998/1997 and 2001/2000. The in-between years also show very slow TFP growth, $0.6 \%$ and $0.1 \%$. On the basis of Table 2 , the average TFP growth rate was only $0.6 \%$ during $1995-2001$ (see also Table 9), which is very close to the figure of $0.64 \%$ obtained using aggregate time series data together with the growth accounting formula. It was to some extent arbitrary when the weight of 0.6 for capital was chosen, but we did notice that Chow's (2002) estimate of capital elasticity was 0.628 in his aggregate time series production function estimations. In the literature, there are also examples that capital share was estimated according to the share of labor cost in terms of GDP. For example, in Hu and Khan (1997), labor's share was taken to be 0.453, Young (2003) used the share of 0.6, and in Wang and Yao (2003) it was 0.5, these figures are all larger than the labor elasticity of 0.4 we used. We need to notice here that the larger the labor's share, the higher the TFP growth estimates. This is because the growth rate of labor force is far less than that of capital stock. For instance, capital grew at $8.8 \%$ and labor force at $2.4 \%$ during $1978-1995$, while these figures are $11.8 \%$ and $1.2 \%$ for $1995-2001$. Thus, a 0.2 difference in the weight for capital will make a great difference when the TFP growth rate is calculated. If we take the growth rate for capital stock of $11.8 \%$ as an example, the increase of the weight from 0.4 to 0.6 for capital will increase the estimate of capital's contribution to GDP growth from $4.72 \%$ to $7.08 \%$. Since GDP grew at $8.2 \%$ per year, after deducting the contributions of capital and labor, not much is left unexplained. The Malmquist index model we are using belongs to the category of the frontier production function estimations, it is thus more consistent with the time series aggregate production function estimation in Chow (2002) than the usual growth accounting methodology using capital and labor shares as weights. In the latter, since the factor shares are used with the growth accounting formula, fairly strong assumptions have to be maintained of perfect competition and profit maximization. These assumptions may not be appropriate for a developing country such as China that is still in its transition to a full-fledged market economy. Therefore, we feel that the result of TFP growth rate of $0.60 \%$ during $1995-2001$ could be trustworthy on both theoretical and empirical grounds. If so, it would be a rather important finding. To check the sensitivity of this estimate, 
in Table 8 the last three rows give estimates of TFP growth rate using three different sets of weights including a weight for human capital. These results reconfirm that TFP grew significantly slower during 1995-2001 than the previous period.

In summary of Tables 1 and 2, it appears that at provincial (average) level, technical efficiency hardly improved during the reform period. But since the dispersion across provinces in technical efficiency had been increasing over time, there must have been some provinces catching up with the best practices and others lagging behind. This can be further confirmed with Table 6. For example, significant efficiency improvement is observed in 11 provinces, accounting for more than $30 \%$ of the total number of production units (provinces). Where technical efficiency improved the most is Hunan province, it was $24 \%$ more efficient in 2001 than in 1979. Efficiency worsened in 15 provinces, among these the Western provinces dominate, for example, Ninxia's efficiency decreased by 40 percentage points. This to a large extent may reflect differences in the capacities of the provinces to efficiently utilize technologies.

\subsection{TFP growth and its components}

By decomposing TFP growth into technical and efficiency change components, we can separate the part of TFP growth due to technical progress from the part due to an improvement in technical efficiency. We can see in Table 2 that productivity growth seem to have been accomplished through "technical progress" rather than improvement in technical efficiency. The accumulated "technical progress" during 1979-2001 is an impressive of $202.64 \%$, while the change in technical efficiency is minus $1.16 \%$. Tables 4 and 5 also show that TFP growth in both the 1980s and the 1990s were accomplished through technical progress not efficiency improvement: the rate of "technical progress" during the 1980s was $6.05 \%$ per year, efficiency change is minus 0.98\%; during the 1990s, average technical progress was $2.16 \%$, efficiency change minus $0.31 \%$. At this point, we can make a rough evaluation on the reliability of our decompositions by following the shift of the provincial production frontiers and by examining the change in the distribution of the production units (provinces) in the input coefficient space.

Figure 1 shows the shifts of the provincial production frontier over time in the input 
coefficient space for selected years, 1980, 1990, and 2001. Three sets of data point plots represent the distribution of the production units in terms of capital-labor ratios for each year chosen. Paying attention to the distribution and the movement of the data points for different years, one can see there are two patterns that appear to be obvious. One is that the distribution of the production units in terms of capital-labor ratio changed from the East-West direction to the North-South direction, indicating a capital deepening process during the 20 -year period. This phenomenon is consistent with the observation in Young (2000) and with the change in capital stock per person and capital productivity reported in Table 8. Another pattern is that although the movement of the production units toward the production frontier is rather visible, according to the decomposition presented in Table 2, the speed of the catching up by average provinces could not match that of the shift of the production frontier.

Judging from the shape and the shift in the direction of the production frontier, there are three things worth mentioning. First, the movement of the 1980s' frontier is far more obvious than that of the 1990s', which is just another way to say that a slow down in technical progress took place in the 1990s (see also Tables 4 and 5). Second, the piecewise linear segments of the production frontier increased gradually (see also Table 7), which is usually an indication of catching up process with some of the production units. In 1980, only Shanghai and Zhejiang were on the production frontier, in 1990 the number of best practices increased to three, Shanghai, Guangdong, and Zhejiang, and finally in 2001 four units were on the frontier, Shanghai, Jiangsu, Anhui, and Fujian. The third interesting observation is that in the direction of capital input coefficient, the production frontiers in the 1990s hardly moved, i.e., no changes in a period of 10 years. Moreover, "capital deepening” appears to have happened on the production frontier. For instance, although Shanghai reduced its labor input coefficient but increased its capital input coefficient. In addition, in the direction of labor input coefficient, the production frontier in the 1990s moved far less than in the 1980s. But fortunately, in the 1990s the largest movement of the frontier is in the direction to the origin, there are 14 provinces moving in this direction, about one half of all the provinces covered in our study.

Based on the above observations, we can say that production frontiers in the 1980s were determined by Shanghai and Zhejiang. In general, the public impression is that Shanghai and 
Zhejiang belongs to the area of high technical efficiency among China's provinces, especially in the case of Shanghai, in some specialized fields it is not very far from the international standards. We thus conclude that it may have some referential values if we interpret the shits of the production frontier during the 1980s as "technical progress". In the 1990s the shift of the production frontier was made possible due to Guangdong, Anhui, and Fujian for the labor-intensive provinces. The problem with these labor-intensive frontier provinces is that their increase in capital productivity was not large while their capital intensity had been increasing and resulted in a reduction in their labor input coefficient. Therefore, we suspect that the shift of the entire frontier may not be due to the improvement in efficiency so that it can be alternatively interpreted as "technical progress" again in a broad sense.

Are the technologies used among the best practice provinces also available to other provinces? Without much specialized information we can take the capital-labor ratio as a rough measure. Figure 1 shows that capital intensity was increasing for all the provinces, this might be taken as the evidence that the adoption of the new technology appears to be a widespread phenomenon (duplications of the industrial structure across provinces, segmented markets, etc). So using provincial production frontiers to measure technical efficiency seems to have considerable referential values. If one is interested in further investigation of the issue, an alternative might be to form a more conservative frontier for the West region separately.

If we ignore what happened to the best practice provinces on the frontier, the fast movement of the average provinces toward the origin and the increase in the capital labor ratio appears to be normal for a country experiencing rapid economic growth and dramatic structural change. But we need to feel worried about the lack of change in the capital input coefficient on the frontier during the 1990s. This means that productivity growth relied heavily on the increase in labor productivity. At the same time, if the increases in labor productivity are solely dependent on the increased capital intensity, the growth pattern will ultimately become one that is factor driven. As shown in Table 8, labor productivity increased on average $7.2 \%$ during 1978-1995, at the same time capital productivity increased 2.2\%. However, during 1995-2001 labor productivity increased on average $7.0 \%$, while capital productivity growth was minus $3.6 \%(\mathrm{Hu}, 2003)$. More interesting is that in comparison with the increase of 7.2\% during 1978-1995, the labor productivity growth 
during 1995-2001 dropped by 0.2-percentage point. Taking account the minus $3.6 \%$ growth in capital productivity, the statistics in Table 8 signals an unavoidable slow down in TFP growth during 1995-2001.

\section{Conclusions}

The findings of our study seem to have made two major contributions to the existing literature. First, TFP growth estimates become more informative when the strong behavioral and institutional assumptions are relaxed by switching from the factor share based traditional growth accounting methodology to a production function based approach. TFP growth was found to be significantly slower during 1995-2001 than the previous period of 1978-1995, raising serious questions about the nature of China's growth patterns in recent years. Second, the decomposition of TFP growth into technical progress and efficiency improvement components has important policy implications, because the distinction is fundamental for policy actions, especially in developing countries. As far as China is concerned, where identifying TFP growth with technical progress can miss the fact that technical efficiency change seems to be the most relevant component of the total change in TFP, and therefore, the introduction of new technologies without having realized the full potential of the existing ones might not be meaningful. As we have seen from our empirical findings that although considerable productivity growth was found for most of the data period, it was accomplished mainly through technical progress rather than through efficiency improvement - a finding that is rather similar to those found using enterprise data (e.g., Zheng, Liu, and Bigsten, 2003).

The issue of technical efficiency improvement at provincial level is particularly interesting for policy actions due to the need for further reforms, i.e., the reform of the SOE sector, of the financial system, and of the governance structure of the political system. So in the foreseeable future, China will still have to face efficiency problems derived from the gradual nature of its economic reform started more than twenty years ago.

On the other hand, technological progress in China are mainly the results of transferring foreign technologies into domestic use, there are little innovation of its own. In other words, during the past 20 years, China took the advantage of the foreign technologies and had the advantages of backwardness, but during the 1990s its provincial production frontier moved 
slowly, indicating a slow down in technical progress. It is not clear whether the slow down in technical progress is due to the government strategies that have been drifting away from their comparative advantages or due to the closing gap with the Western countries in terms of the levels of technologies. However, as Liu (2000) points out that China's future productivity growth depends ultimately on its ability to innovate in science and technology, which, in turn, depends on government policies towards entrepreneurial activity and research and development, and on the establishment of market-based institutions.

\section{References}

Bhattasali, Deepak, Sustaining China's Development: Some Issues, Presentation to Tsinghua University 90th Anniversary Celebrations Seminar Series, Beijing, People' s Republic of China, April 24, 2001.

CCER, Retrospect and Perspectives of the Financial System Reform in China. China Center for Economic Research (in Chinese). Peking University, the group for strategic economic development study, working paper series, C2000005, April, 2000.

Chow, Gregory; Lin, An-loh, Accounting for Economic Growth in Taiwan and Mainland China: A Comparative Analysis, Journal of Comparative Economics, September 2002, v. 30, iss. 3 , pp. 507-30.

Chow, Gregory C.; Li, Kui-Wai; China's Economic Growth: 1952-2010; Economic Development and Cultural Change, October 2002, v. 51, iss. 1, pp. 247-56

Chow, Gregory C.; Capital Formation and Economic Growth in China; Quarterly Journal of Economics, August 1993, v. 108, iss. 3, pp. 809-42.

Chow, Gregory C.; Economic Analysis of the People's Republic of China; Journal of Economic Education, Winter 1988, v. 19, iss. 1, pp. 53-64.

Ezaki, Mitsuo and Sun, Lin, Growth Accounting in China for National, Regional, and Provincial Economies: 1981-1995. Asian Economic Journal, March 1999, v. 13, iss. 1, pp. 39-71.

Farrell, M. J., "The measurement of productive efficiency, J. R. Statist. Soc. Series A, 120,III, 253-281, 1957.

Felipe, Jesus, Total Factor Productivity Growth in East Asia: A critical Survey. The Journal 
of Development Studies, Vol. 35, No.4, April 19999, pp. 1-41.

Färe, Rolf, Grosskopf, Shawna, Norris, Mary, and Zhang Zhongyang, "Productivity Growth, Technical Progress, and Efficiency Change in Industrialized Countries.” Am. Econ. Rev. 84, 1:66-83, Mar. 1994.

Färe, Rolf and Grosskopf, Shawna, Intertemporal Production Frontiers: With Dynamic DEA. Boston/London/Dordrecht: Kluwer Academic Publishers, 1996.

Førsund, Finn R. and Hjalmarsson, "Generalized Farrell Measures of Efficiency: An Application to Milk Processing In Swedish Dairy Plants.” Econ. J. 89, 354:294-315, June 1979.

Heytens, Paul and Zebregs, Harm, "How Fast Can China Grow?", in China: Competing in the global Economy. Ed. Wangda Tseng and Marjus Rodlauer, International Monetary Fund, Washington, 2003.

Hu, Angang, Macroeconomic Policy and Employment Promotion: Economic Growth and Employment Growth, International Labor Organization and Social Welfare Department, China Employment Forum, April 7-9, 2003.

$\mathrm{Hu}$, Angang, Economic Growth in the Future will be Dependent on TFP (in Chinese), China Net, July 04, 2002. http://www.china.org.cn/chinese/2002/Jul/168635.htm

$\mathrm{Hu}$, Zuliu F and Khan, Mohsin S, Why is China growing so fast? IMF Staff Papers; Mar 1997; 44, 1; pg. 103.

Li, Rongrong, Deepening State Enterprise Reform (in Chinese). In Fan, Wei and Li, Yumei: Interview with Li, Rongrong, the Chairman of the State Assets Supervision Commission of State Council, Enterprise Party Construction (Qiye Dangjian), No.12, 2003. http://www.dangjian.org/singl info1.asp?content id=619

Krugman, Paul, The myth of Asia's miracle, Foreign Affairs,Vol73, 6: pg. 62, 1994.

Liu, Zhiqiang, The Nature of China's Economic Growth in the Past Two Decades. Post-Communist Economies, Vol. 12, No. 2, 2000.

Mao, Weining and Koo, Won W., "Productivity Growth, Technological Progress, and Efficiency Change in Chinese Agriculture after Rural Economic Reforms: A DEA Approach.” China Econ. Rev. 8, 2:157-74, Fall 1997. 
OECD, China in the World Economy: The Domestic Policy Challenges. Synthesis Report, Organization for Economic Co-operation and Development, 2002.

Sachs, Jeffrey D., Woo, Wing Thye, Understanding China's Economic Performance. NBER Working Paper Series, Working Paper 5935, 1997.

SSB, China Statistical Yearbook. State Statistical Bureau, Beijing: China Statistics Press, 2000.

SSB, Collections of Statistics for the 50-Year Anniversary of New China. State Statistical Bureau, Beijing: China Statistics Press, 1991.

Wang, Shaoguang and Hu, Angang, 1999. China: The Political Economy of Unbalanced Development. Beijing: China Planning Publishing House.

Wang, Xiaolu; Meng, Lian; A Reevaluation of China's Economic Growth; China Economic Review, v. 12, iss. 4, pp. 338-46, 2001.

Wang, Yan and Yudong Yao, Sources of China’s economic growth 1952-1999: incorporating human capital accumulation. China Economic Review, 14 (2003) 32-52.

World Bank, China 2020: Development Challenges in the New Century. Washington D.C.: The World Bank, 1997.

Wu, Yanrui, Has Productivity Contributed to China's Growth? Pacific Economic Review, Volume 8 Issue 1 Page 15, January 2003.

$\mathrm{Wu}$, Yanrui, Is China's Growth Sustainable? A Productivity Analysis, China Economic Review, 11, 278-296, 2000.

Young, Alwyn, Gold into Base Metals: Productivity Growth in the People's Republic of China during the Reform Period, Journal of Political Economy, 2003, vol. 111, no. 6. Young, Alwyn, 2000, The Razor's Edge: Distortions and Incremental Reform in the People's Republic of China", Massachusetts: Quarterly Journal of Economics, Vol. CXV, Issue 4 (Number).

Zheng, Jinghai, Liu, Xiaoxuan and Bigsten, Arne, "Efficiency, Technical Progress, and Best Practice in Chinese State Enterprises (1980-1994).”J. Comp. Econ., March 2003. 
Table 1. Technical Efficiency (Country Average, 1979-2001)

\begin{tabular}{|c|c|c|c|c|c|c|}
\hline Year & $\begin{array}{c}\text { Technical } \\
\text { Efficiency } \\
\text { (CRS) }\end{array}$ & $\begin{array}{c}\text { Technical } \\
\text { Efficiency } \\
\text { (VRS) }\end{array}$ & $\begin{array}{c}\text { Scale } \\
\text { Efficiency }\end{array}$ & $\begin{array}{c}\text { Technical } \\
\text { Efficiency } \\
\text { (CRS, Min) }\end{array}$ & $\begin{array}{c}\text { Technical } \\
\text { Efficiency } \\
\text { (VRS, Min) }\end{array}$ & $\begin{array}{c}\text { Technical } \\
\text { Efficiency } \\
\text { (CRS,STD) }\end{array}$ \\
\hline 1979 & 0.8362 & 0.8762 & 1.0491 & 0.7486 & 0.7524 & 0.0683 \\
\hline 1980 & 0.8088 & 0.8491 & 1.0507 & 0.6864 & 0.6946 & 0.0856 \\
\hline 1981 & 0.7884 & 0.8219 & 1.0434 & 0.6610 & 0.6644 & 0.0957 \\
\hline 1982 & 0.7892 & 0.8324 & 1.0555 & 0.6709 & 0.6821 & 0.0858 \\
\hline 1983 & 0.8065 & 0.8562 & 1.0620 & 0.6518 & 0.6962 & 0.0817 \\
\hline 1984 & 0.7936 & 0.8399 & 1.0591 & 0.6174 & 0.6604 & 0.0925 \\
\hline 1985 & 0.7599 & 0.8105 & 1.0675 & 0.5724 & 0.6271 & 0.0959 \\
\hline 1986 & 0.7532 & 0.8116 & 1.0817 & 0.5747 & 0.6631 & 0.1002 \\
\hline 1987 & 0.7663 & 0.8241 & 1.0814 & 0.5581 & 0.6525 & 0.1082 \\
\hline 1988 & 0.7845 & 0.8322 & 1.0685 & 0.5538 & 0.6479 & 0.1128 \\
\hline 1989 & 0.8251 & 0.8632 & 1.0521 & 0.5619 & 0.6434 & 0.1035 \\
\hline 1990 & 0.8297 & 0.8656 & 1.0488 & 0.5465 & 0.6297 & 0.1025 \\
\hline 1991 & 0.7915 & 0.8364 & 1.0667 & 0.5143 & 0.6187 & 0.1155 \\
\hline 1992 & 0.7881 & 0.8345 & 1.0717 & 0.4919 & 0.6094 & 0.1253 \\
\hline 1993 & 0.7933 & 0.8415 & 1.0769 & 0.4843 & 0.6034 & 0.1327 \\
\hline 1994 & 0.8058 & 0.8468 & 1.0674 & 0.4839 & 0.6066 & 0.1404 \\
\hline 1995 & 0.8111 & 0.8547 & 1.0700 & 0.4907 & 0.6174 & 0.1438 \\
\hline 1996 & 0.8180 & 0.8633 & 1.0708 & 0.4896 & 0.6170 & 0.1443 \\
\hline 1997 & 0.8171 & 0.8619 & 1.0710 & 0.4843 & 0.6149 & 0.1485 \\
\hline 1998 & 0.8231 & 0.8644 & 1.0662 & 0.4917 & 0.6202 & 0.1484 \\
\hline 1999 & 0.8241 & 0.8635 & 1.0638 & 0.5015 & 0.6360 & 0.1494 \\
\hline 2000 & 0.8242 & 0.8627 & 1.0635 & 0.4989 & 0.6376 & 0.1521 \\
\hline 2001 & 0.8215 & 0.8427 & 1.0347 & 0.4988 & 0.5636 & 0.1545 \\
\hline
\end{tabular}


Table 2.Malmquist Productivity Index and its Components (coutnry average, 1979-2001)

\begin{tabular}{|c|c|c|c|c|c|}
\hline Year & $\begin{array}{l}\text { Productivity } \\
\text { Growth }\end{array}$ & $\begin{array}{l}\text { Technical } \\
\text { Progress }\end{array}$ & $\begin{array}{c}\text { Efficiency } \\
\text { Change } \\
\text { (CRS) }\end{array}$ & $\begin{array}{l}\text { Scale Efficiency } \\
\text { Change }\end{array}$ & $\begin{array}{c}\text { Efficiency } \\
\text { Change } \\
\text { (VRS) }\end{array}$ \\
\hline $1980 / 1979$ & 1.0866 & 1.1247 & 0.9663 & 0.9988 & 0.9677 \\
\hline $1981 / 1980$ & 1.0506 & 1.0774 & 0.9749 & 1.0078 & 0.9677 \\
\hline $1982 / 1981$ & 1.0762 & 1.0729 & 1.0030 & 0.9895 & 1.0138 \\
\hline $1983 / 1982$ & 1.0717 & 1.0469 & 1.0237 & 0.9978 & 1.0259 \\
\hline $1984 / 1983$ & 1.1091 & 1.1286 & 0.9829 & 1.0026 & 0.9804 \\
\hline $1985 / 1984$ & 1.0647 & 1.1122 & 0.9572 & 0.9929 & 0.9641 \\
\hline $1986 / 1985$ & 1.0060 & 1.0203 & 0.9861 & 1.0006 & 0.9854 \\
\hline $1987 / 1986$ & 1.0352 & 1.0192 & 1.0157 & 1.0043 & 1.0113 \\
\hline $1988 / 1987$ & 1.0447 & 1.0207 & 1.0236 & 1.0128 & 1.0110 \\
\hline $1989 / 1988$ & 1.0040 & 1.0007 & 1.0033 & 1.0023 & 1.0011 \\
\hline $1990 / 1989$ & 1.0139 & 1.0201 & 0.9943 & 1.0011 & 0.9931 \\
\hline $1991 / 1990$ & 1.0296 & 1.0821 & 0.9517 & 0.9921 & 0.9593 \\
\hline $1992 / 1991$ & 1.0648 & 1.0712 & 0.9941 & 0.9990 & 0.9950 \\
\hline $1993 / 1992$ & 1.0366 & 1.0313 & 1.0055 & 1.0000 & 1.0056 \\
\hline $1994 / 1993$ & 1.0282 & 1.0193 & 1.0089 & 1.0067 & 1.0022 \\
\hline $1995 / 1994$ & 1.0192 & 1.0201 & 0.9994 & 1.0025 & 0.9969 \\
\hline $1996 / 1995$ & 1.0200 & 1.0143 & 1.0058 & 1.0031 & 1.0027 \\
\hline $1997 / 1996$ & 1.0131 & 1.0173 & 0.9959 & 1.0024 & 0.9936 \\
\hline $1998 / 1997$ & 0.9994 & 1.0077 & 0.9917 & 1.0031 & 0.9887 \\
\hline $1999 / 1998$ & 1.0061 & 1.0164 & 0.9896 & 1.0046 & 0.9852 \\
\hline $2000 / 1999$ & 1.0010 & 1.0111 & 0.9899 & 1.0026 & 0.9874 \\
\hline $2001 / 2000$ & 0.9964 & 1.0078 & 0.9886 & 1.0038 & 0.9849 \\
\hline $2001 / 1979$ & 1.9947 & 2.0264 & 0.9862 & 1.0173 & 0.9663 \\
\hline
\end{tabular}


Table 3. Average Technical Efficiency in Chinese provinces in 1980s and 1990s

\begin{tabular}{|c|c|c|c|c|c|c|}
\hline \multirow{2}{*}{ Provinces } & \multicolumn{3}{|c|}{$1979-1990$} & \multicolumn{3}{|c|}{ 1991-2001 } \\
\hline & $\begin{array}{c}\text { Efficiency } \\
\text { (CRS) }\end{array}$ & $\begin{array}{c}\text { Efficiency } \\
\text { (VRS) }\end{array}$ & $\begin{array}{c}\text { Scale } \\
\text { Efficiency }\end{array}$ & $\begin{array}{c}\text { Efficiency } \\
\text { (CRS) }\end{array}$ & $\begin{array}{c}\text { Efficiency } \\
\text { (VRS) }\end{array}$ & $\begin{array}{c}\text { Scale } \\
\text { Efficiency }\end{array}$ \\
\hline Beijing & 0.8974 & 0.9051 & 1.0086 & 0.8477 & 0.8627 & 1.0176 \\
\hline Tianjing & 0.8501 & 0.8622 & 1.0145 & 0.8853 & 0.9185 & 1.0377 \\
\hline Hebei & 0.7385 & 0.7888 & 1.0693 & 0.8026 & 0.8309 & 1.0351 \\
\hline Shanxi & 0.7046 & 0.7096 & 1.0072 & 0.6575 & 0.6655 & 1.0124 \\
\hline Liaonin & 0.8849 & 0.9124 & 1.0319 & 0.8676 & 0.8742 & 1.0076 \\
\hline Jilin & 0.8387 & 0.8485 & 1.0115 & 0.8100 & 0.8244 & 1.0179 \\
\hline Heilongjiang & 0.8194 & 0.8212 & 1.0023 & 0.7919 & 0.7978 & 1.0078 \\
\hline Shanghai & 1.0000 & 1.0000 & 1.0000 & 1.0000 & 1.0000 & 1.0000 \\
\hline Jiangsu & 0.8621 & 0.9860 & 1.1465 & 0.9778 & 1.0000 & 1.0246 \\
\hline Zhejiang & 1.0000 & 1.0000 & 1.0000 & 0.9623 & 0.9674 & 1.0054 \\
\hline Anhui & 0.7918 & 0.7986 & 1.0087 & 0.9186 & 0.9231 & 1.0051 \\
\hline Fujian & 0.8520 & 0.8613 & 1.0110 & 0.9793 & 0.9841 & 1.0052 \\
\hline Jiangxi & 0.7614 & 0.7668 & 1.0069 & 0.9138 & 0.9286 & 1.0163 \\
\hline Shandong & 0.7941 & 0.9257 & 1.1666 & 0.9185 & 0.9732 & 1.0613 \\
\hline Henan & 0.7818 & 0.8912 & 1.1412 & 0.8783 & 0.9016 & 1.0267 \\
\hline Hubei & 0.7989 & 0.8294 & 1.0387 & 0.8517 & 0.8695 & 1.0206 \\
\hline Hunan & 0.6973 & 0.7453 & 1.0701 & 0.8606 & 0.8644 & 1.0045 \\
\hline Guangdong & 0.8864 & 0.9587 & 1.0843 & 0.9617 & 0.9734 & 1.0125 \\
\hline Guangxi & 0.7236 & 0.7336 & 1.0140 & 0.8706 & 0.8924 & 1.0252 \\
\hline Hainan & 0.7883 & 0.8639 & 1.0962 & 0.6868 & 0.7829 & 1.1392 \\
\hline Sichuan & 0.7575 & 0.8772 & 1.1596 & 0.8129 & 0.8305 & 1.0216 \\
\hline Guizhou & 0.7267 & 0.7464 & 1.0268 & 0.7710 & 0.8118 & 1.0527 \\
\hline Yunnan & 0.7424 & 0.7527 & 1.0135 & 0.8063 & 0.8230 & 1.0204 \\
\hline Xizang & 0.7687 & 1.0000 & 1.3305 & 0.5557 & 0.9847 & 1.7739 \\
\hline Shan_xi & 0.7204 & 0.7254 & 1.0068 & 0.6883 & 0.6935 & 1.0076 \\
\hline Guansu & 0.7203 & 0.7320 & 1.0162 & 0.7196 & 0.7393 & 1.0274 \\
\hline Qinghai & 0.6352 & 0.6979 & 1.1034 & 0.4936 & 0.6134 & 1.2430 \\
\hline Ninxia & 0.7385 & 0.8290 & 1.1255 & 0.5442 & 0.6670 & 1.2251 \\
\hline Xingjiang & 0.7769 & 0.7986 & 1.0281 & 0.6762 & 0.7110 & 1.0513 \\
\hline Average & 0.7951 & 0.8403 & 1.0600 & 0.8107 & 0.8520 & 1.0657 \\
\hline
\end{tabular}


Table 4. TFP Growth, Technical Efficiency, and Efficiency Change of Chinese Provinces in 1980s

\begin{tabular}{|c|c|c|c|c|c|}
\hline Provinces & $\begin{array}{l}\text { TFP Growth } \\
\text { (CRS) }\end{array}$ & $\begin{array}{c}\text { Tech Progress } \\
(\mathrm{CRS})\end{array}$ & $\begin{array}{c}\text { Eff Change } \\
(\mathrm{CRS})\end{array}$ & $\begin{array}{l}\text { Scale Eff } \\
\text { Change }\end{array}$ & $\begin{array}{c}\text { Eff Change } \\
\text { (VRS) }\end{array}$ \\
\hline Beijing & 1.0327 & 1.0423 & 0.9911 & 1.0002 & 0.9909 \\
\hline Tianjing & 1.0250 & 1.0431 & 0.9828 & 0.9998 & 0.9830 \\
\hline Hebei & 1.0515 & 1.0642 & 0.9891 & 1.0016 & 0.9874 \\
\hline Shanxi & 1.0336 & 1.0617 & 0.9744 & 0.9999 & 0.9745 \\
\hline Liaonin & 1.0429 & 1.0524 & 0.9913 & 0.9994 & 0.9918 \\
\hline Jilin & 1.0482 & 1.0602 & 0.9898 & 1.0002 & 0.9897 \\
\hline Heilongjiang & 1.0362 & 1.0522 & 0.9854 & 0.9999 & 0.9855 \\
\hline Shanghai & 1.0503 & 1.0503 & 1.0000 & 1.0000 & 1.0000 \\
\hline Jiangsu & 1.0631 & 1.0628 & 1.0008 & 0.9966 & 1.0042 \\
\hline Zhejiang & 1.0606 & 1.0657 & 0.9949 & 0.9997 & 0.9952 \\
\hline Anhui & 1.0449 & 1.0600 & 0.9865 & 1.0014 & 0.9849 \\
\hline Fujian & 1.0733 & 1.0671 & 1.0060 & 1.0003 & 1.0056 \\
\hline Jiangxi & 1.0547 & 1.0631 & 0.9932 & 0.9996 & 0.9936 \\
\hline Shandong & 1.0609 & 1.0663 & 0.9953 & 1.0005 & 0.9951 \\
\hline Henan & 1.0550 & 1.0611 & 0.9954 & 1.0007 & 0.9947 \\
\hline Hubei & 1.0588 & 1.0639 & 0.9955 & 1.0025 & 0.9930 \\
\hline Hunan & 1.0516 & 1.0625 & 0.9913 & 1.0027 & 0.9886 \\
\hline Guangdong & 1.0772 & 1.0650 & 1.0120 & 1.0025 & 1.0096 \\
\hline Guangxi & 1.0575 & 1.0604 & 0.9984 & 0.9994 & 0.9990 \\
\hline Hainan & 1.0573 & 1.0672 & 0.9917 & 1.0022 & 0.9900 \\
\hline Sichuan & 1.0484 & 1.0599 & 0.9904 & 1.0031 & 0.9874 \\
\hline Guizhou & 1.0559 & 1.0604 & 0.9970 & 0.9998 & 0.9972 \\
\hline Yunnan & 1.0633 & 1.0604 & 1.0046 & 0.9998 & 1.0048 \\
\hline Xizang & 1.0379 & 1.0668 & 0.9722 & 0.9915 & 0.9801 \\
\hline Shan_xi & 1.0509 & 1.0660 & 0.9866 & 1.0002 & 0.9865 \\
\hline Guansu & 1.0429 & 1.0638 & 0.9818 & 1.0002 & 0.9817 \\
\hline Qinghai & 1.0143 & 1.0585 & 0.9588 & 1.0004 & 0.9591 \\
\hline Ninxia & 1.0309 & 1.0631 & 0.9705 & 1.0020 & 0.9693 \\
\hline Xingjiang & 1.0516 & 1.0630 & 0.9899 & 1.0003 & 0.9896 \\
\hline Average & 1.0494 & 1.0605 & 0.9902 & 1.0002 & 0.9901 \\
\hline
\end{tabular}


Table 5. TFP Growth, Technical Efficiency, and Efficiency Change of Chinese Provinces in 1990s

\begin{tabular}{|c|c|c|c|c|c|}
\hline Provinces & $\begin{array}{l}\text { TFP Growth } \\
\text { (CRS) }\end{array}$ & $\begin{array}{c}\text { Tech Progress } \\
(\mathrm{CRS})\end{array}$ & $\begin{array}{c}\text { Eff Change } \\
(\mathrm{CRS})\end{array}$ & $\begin{array}{c}\text { Scale Eff } \\
\text { Change }\end{array}$ & $\begin{array}{c}\text { Eff Change } \\
(\mathrm{VRS})\end{array}$ \\
\hline Beijing & 1.0095 & 1.0274 & 0.9827 & 1.0031 & 0.9797 \\
\hline Tianjing & 1.0486 & 1.0323 & 1.0161 & 1.0040 & 1.0121 \\
\hline Hebei & 1.0140 & 1.0157 & 0.9982 & 0.9962 & 1.0021 \\
\hline Shanxi & 1.0288 & 1.0225 & 1.0061 & 1.0031 & 1.0029 \\
\hline Liaonin & 1.0425 & 1.0383 & 1.0042 & 1.0002 & 1.0040 \\
\hline Jilin & 1.0333 & 1.0242 & 1.0092 & 1.0013 & 1.0079 \\
\hline Heilongjiang & 1.0375 & 1.0293 & 1.0085 & 1.0016 & 1.0068 \\
\hline Shanghai & 1.0794 & 1.0794 & 1.0000 & 1.0000 & 1.0000 \\
\hline Jiangsu & 1.0546 & 1.0393 & 1.0144 & 1.0144 & 1.0000 \\
\hline Zhejiang & 1.0118 & 1.0252 & 0.9869 & 1.0015 & 0.9854 \\
\hline Anhui & 1.0242 & 1.0063 & 1.0178 & 0.9978 & 1.0200 \\
\hline Fujian & 1.0259 & 1.0159 & 1.0098 & 1.0016 & 1.0081 \\
\hline Jiangxi & 1.0099 & 1.0063 & 1.0035 & 1.0036 & 1.0000 \\
\hline Shandong & 1.0240 & 1.0153 & 1.0083 & 0.9945 & 1.0141 \\
\hline Henan & 1.0129 & 1.0063 & 1.0066 & 0.9981 & 1.0085 \\
\hline Hubei & 1.0246 & 1.0180 & 1.0064 & 1.0025 & 1.0040 \\
\hline Hunan & 1.0165 & 1.0063 & 1.0101 & 0.9979 & 1.0122 \\
\hline Guangdong & 1.0267 & 1.0361 & 0.9909 & 0.9969 & 0.9940 \\
\hline Guangxi & 1.0024 & 1.0063 & 0.9958 & 1.0054 & 0.9905 \\
\hline Hainan & 1.0159 & 1.0335 & 0.9830 & 1.0076 & 0.9756 \\
\hline Sichuan & 0.9955 & 1.0063 & 0.9892 & 0.9989 & 0.9903 \\
\hline Guizhou & 0.9830 & 1.0063 & 0.9769 & 1.0081 & 0.9691 \\
\hline Yunnan & 0.9796 & 1.0063 & 0.9734 & 1.0053 & 0.9683 \\
\hline Xizang & 1.0188 & 1.0252 & 0.9942 & 1.0018 & 0.9925 \\
\hline Shan_xi & 0.9943 & 1.0098 & 0.9848 & 1.0027 & 0.9822 \\
\hline Guansu & 0.9893 & 1.0063 & 0.9832 & 1.0056 & 0.9777 \\
\hline Qinghai & 1.0176 & 1.0247 & 0.9934 & 1.0128 & 0.9809 \\
\hline Ninxia & 1.0062 & 1.0275 & 0.9796 & 1.0117 & 0.9683 \\
\hline Xingjiang & 1.0087 & 1.0316 & 0.9780 & 1.0029 & 0.9752 \\
\hline Average & 1.0185 & 1.0216 & 0.9969 & 1.0028 & 0.9942 \\
\hline
\end{tabular}


Table 6. TFP Growth, Technical Efficiency, and Efficiency Change of Chinese Provinces (Accumulate, 1979-2001)

\begin{tabular}{|c|c|c|c|c|c|}
\hline Provinces & $\begin{array}{l}\text { TFP Growth } \\
\text { (CRS) }\end{array}$ & $\begin{array}{c}\text { Tech Progress } \\
\text { (CRS) }\end{array}$ & $\begin{array}{c}\text { Eff Change } \\
\text { (CRS) }\end{array}$ & Scale Eff Change & $\begin{array}{c}\text { Eff Change } \\
\text { (VRS) }\end{array}$ \\
\hline Beijing & 2.5594 & 3.0169 & 0.8484 & 1.0015 & 0.8471 \\
\hline Tianjing & 2.9736 & 2.8110 & 1.0578 & 0.9973 & 1.0607 \\
\hline Hebei & 1.8169 & 1.8923 & 0.9602 & 1.0431 & 0.9205 \\
\hline Shanxi & 1.6706 & 1.9051 & 0.8769 & 1.0020 & 0.8752 \\
\hline Liaonin & 2.0812 & 2.1073 & 0.9876 & 1.0161 & 0.9719 \\
\hline Jilin & 1.9255 & 1.9159 & 1.0050 & 0.9962 & 1.0088 \\
\hline Heilongiiang & 1.8742 & 1.9587 & 0.9568 & 1.0004 & 0.9565 \\
\hline Shanghai & 3.8889 & 3.8889 & 1.0000 & 1.0000 & 1.0000 \\
\hline Jiangsu & 2.5611 & 2.1196 & 1.2083 & 1.1510 & 1.0498 \\
\hline Zhejiang & 1.6375 & 1.8704 & 0.8755 & 0.9964 & 0.8787 \\
\hline Anhui & 2.2411 & 1.8042 & 1.2421 & 1.0186 & 1.2195 \\
\hline Fujian & 2.3403 & 1.8635 & 1.2558 & 1.0084 & 1.2454 \\
\hline Jiangxi & 2.1925 & 1.8395 & 1.1919 & 0.9985 & 1.1937 \\
\hline Shandong & 2.2605 & 1.8717 & 1.2077 & 1.1065 & 1.0915 \\
\hline Henan & 2.2309 & 1.7996 & 1.2397 & 1.0996 & 1.1273 \\
\hline Hubei & 2.0611 & 1.8890 & 1.0911 & 1.0323 & 1.0569 \\
\hline Hunan & 2.2695 & 1.8263 & 1.2426 & 1.0730 & 1.1581 \\
\hline Guangdong & 2.2165 & 2.0149 & 1.1001 & 1.0464 & 1.0514 \\
\hline Guangxi & 2.0738 & 1.7656 & 1.1746 & 0.9993 & 1.1754 \\
\hline Hainan & 1.4799 & 1.9025 & 0.7779 & 0.9922 & 0.7840 \\
\hline Sichuan & 1.8044 & 1.8105 & 0.9966 & 1.1226 & 0.8878 \\
\hline Guizhou & 1.6644 & 1.7545 & 0.9487 & 1.0049 & 0.9441 \\
\hline Yunnan & 1.7892 & 1.7868 & 1.0014 & 1.0028 & 0.9985 \\
\hline Xizang & 1.2664 & 1.8496 & 0.6847 & 0.8229 & 0.8321 \\
\hline Shan_xi & 1.6346 & 1.8679 & 0.8751 & 1.0032 & 0.8723 \\
\hline Guansu & 1.5783 & 1.8843 & 0.8376 & 1.0060 & 0.8326 \\
\hline Qinghai & 1.1610 & 1.8996 & 0.6112 & 0.9687 & 0.6310 \\
\hline Ninxia & 1.1488 & 1.9035 & 0.6035 & 0.9962 & 0.6058 \\
\hline Xingjiang & 1.4430 & 1.9466 & 0.7413 & 0.9953 & 0.7448 \\
\hline Average & 1.9947 & 2.0264 & 0.9862 & 1.0173 & 0.9663 \\
\hline
\end{tabular}


Table 7. Best Practice Provinces over Time

\begin{tabular}{|c|c|c|c|}
\hline Year & Best Practice Provinces & Year & Best Practice Provinces \\
\hline 1979 & Shanghai & 1991 & Shanghai, Zhengjiang, Guandong \\
\hline 1980 & Shanghai, Zhengjiang & 1992 & Shanghai, Zhengjiang, Guandong \\
\hline 1981 & Shanghai, Zhengjiang & 1993 & Shanghai, Zhengjiang, Guandong \\
\hline 1982 & Shanghai, Zhengjiang & 1994 & $\begin{array}{l}\text { Shanghai, Zhengjiang, Fujian, } \\
\text { Guandong }\end{array}$ \\
\hline 1983 & Shanghai, Zhengjiang & 1995 & $\begin{array}{l}\text { Shanghai, Zhengjiang, Fujian, } \\
\text { Guandong }\end{array}$ \\
\hline 1984 & Shanghai, Zhengjiang & 1996 & Shanghai, Jiangsu, Fujian \\
\hline 1985 & Shanghai, Zhengjiang & 1997 & Shanghai, Jiangsu, Fujian \\
\hline 1986 & Shanghai, Zhengjiang & 1998 & Shanghai, Jiangsu, Fujian \\
\hline 1987 & Shanghai, Zhengjiang & 1999 & Shanghai, Jiangsu, Anhui, Fujian \\
\hline 1988 & Shanghai, Zhengjiang & 2000 & Shanghai, Jiangsu, Anhui, Fujian \\
\hline 1989 & Shanghai, Guandong & 2001 & Shanghai, Jiangsu, Anhui, Fujian \\
\hline 1990 & Shanghai, Zhengjiang, Guandong & & \\
\hline
\end{tabular}

Table 8. Sources of China's Economic Growth（1952-2001）

\begin{tabular}{cccc} 
(Source: $\mathrm{Hu}$, 2003) & \multicolumn{3}{c}{ Unit: \% } \\
\hline & $1952-1978$ & $1978-1995$ & $1995-2001$ \\
\hline Population & 2.0 & 1.4 & 0.9 \\
GDP & 4.7 & 9.8 & 8.2 \\
GDP per capita & 2.7 & 8.4 & 7.3 \\
Employment & 2.6 & 2.6 & 1.2 \\
Labor Productivity & 2.1 & 7.2 & 7.0 \\
Capital Stock & 11.5 & 9.3 & 11.8 \\
Human Capital & 4.1 & 2.2 & 2.8 \\
Capital Productivity & -6.8 & 0.5 & -3.6 \\
Capital per capita & 8.9 & 6.7 & 10.6 \\
TFPa & -1.9 & $4.64(47.3)$ & $2.28(27.8)$ \\
TFPb & & $3.95(40.3)$ & $1.30(15.9)$ \\
TFPc & & $3.26(33.3)$ & $0.32(3.9)$ \\
\hline
\end{tabular}

Note: TFP was calculated using three sets of weights: a) capital weight 0.4 , labor weight 0.3 ; human capital weight 0.3 ; b) $0.5,0.25,0.25$; c) $0.6,0.2,0.2$. Figures in parentheses are the contributions of the TFP to GDP growth. 
Table 9 TFP Growth and its Components during Different Periods of Economic Reform in China

\begin{tabular}{ccccccccccc}
\hline \multirow{2}{*}{ Periods } & \multicolumn{3}{c}{ TFP Growth } & \multicolumn{3}{c}{ Technical Efficiency Change } & \multicolumn{3}{c}{ Technical Progress } \\
\cline { 2 - 9 } & Mean & Std & Variation & Mean & Std & Variation & Mean & Std & Variation \\
\hline $1979-1990$ & 1.0494 & 0.0139 & 1.3274 & 0.9902 & 0.0112 & 1.1286 & 1.0605 & 0.0065 & 0.6133 \\
$1991-2001$ & 1.0185 & 0.0215 & 2.1092 & 0.9969 & 0.0131 & 1.3130 & 1.0216 & 0.0159 & 1.5527 \\
$1979-1995$ & 1.0463 & 0.0128 & 1.2197 & 0.9932 & 0.0113 & 1.1402 & 1.0542 & 0.0059 & 0.5600 \\
$1996-2001$ & 1.0060 & 0.0256 & 2.5414 & 0.9936 & 0.0138 & 1.3914 & 1.0124 & 0.0172 & 1.6992 \\
$1979-1984$ & 1.0765 & 0.0191 & 1.7766 & 0.9847 & 0.0139 & 1.4108 & 1.0938 & 0.0100 & 0.9110 \\
$1985-1990$ & 1.0222 & 0.0172 & 1.6801 & 0.9958 & 0.0162 & 1.6283 & 1.0272 & 0.0084 & 0.8200 \\
$1991-1995$ & 1.0372 & 0.0234 & 2.2566 & 1.0020 & 0.0225 & 2.2450 & 1.0354 & 0.0166 & 1.6028 \\
$1996 *-2001$ & 1.0060 & 0.0256 & 2.5414 & 0.9936 & 0.0138 & 1.3914 & 1.0124 & 0.0172 & 1.6992 \\
\hline
\end{tabular}




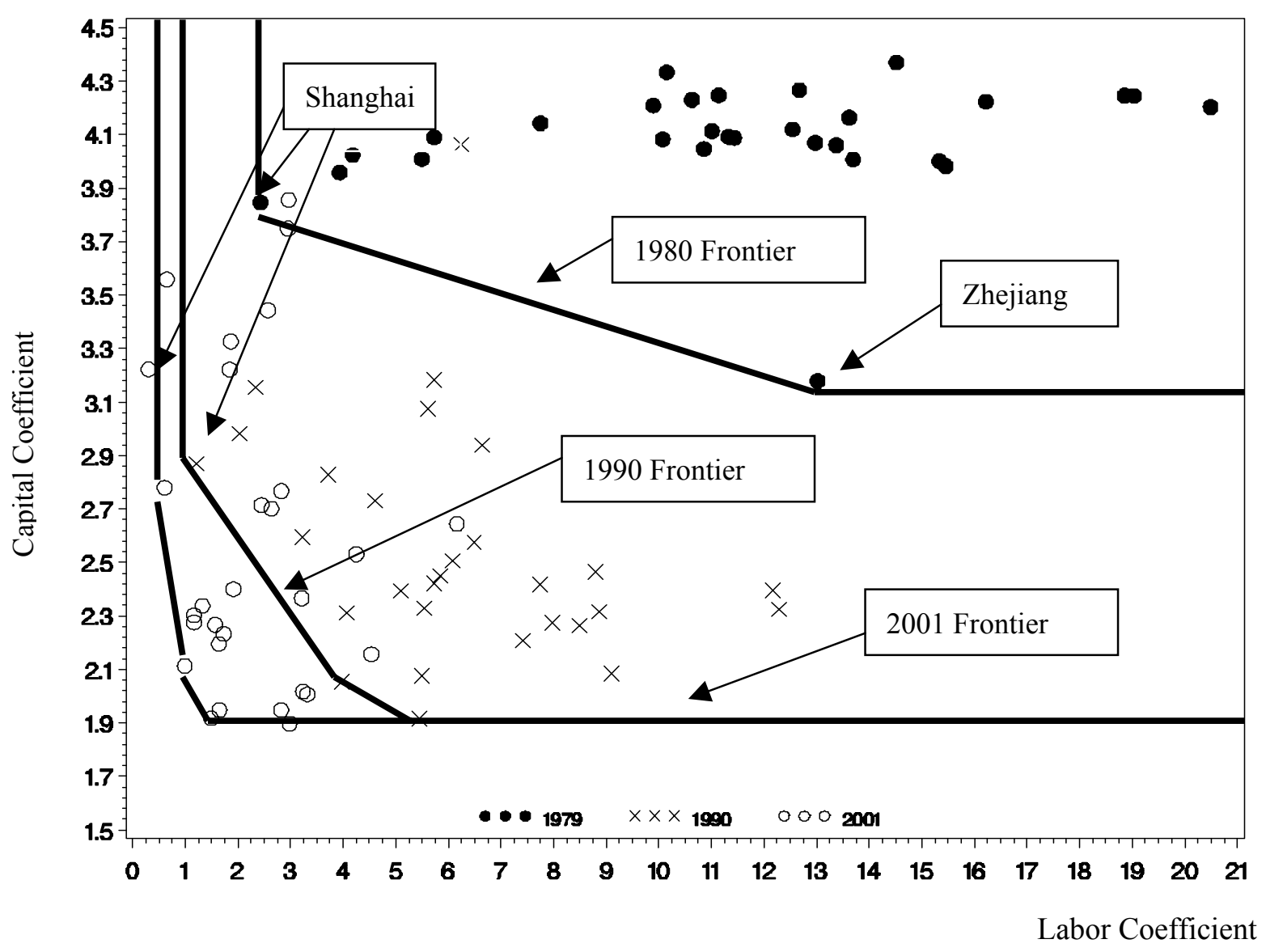

Figure 1. The Movement of production frontiers to the origin and the change of the provincial labor-capital ratios during economic reform (efficiency frontiers in input coefficient space). 